\title{
Retrospective Reports of Parental Socialization of Physical Pain During Childhood Predicting Emerging Adults' Current Coping With Pain
}

\author{
Julie DiNuoscio ${ }^{1}$, Vaishali V. Raval ${ }^{1} \&$ Bethany L. Walker $^{1}$ \\ ${ }^{1}$ Department of Psychology, Miami University, Oxford, Ohio, USA \\ Correspondence: Vaishali V. Raval, Department of Psychology, Miami University, 90 N Patterson Ave, Oxford, \\ Ohio 45056, USA. Tel: 1-513-529-6209. E-mail: ravalvv@miamioh.edu
}

Received: July 15, 2019 Accepted: August 14, 2019 Online Published: August 21, 2019

doi:10.5539/jedp.v9n2p74

URL: http://doi.org/10.5539/jedp.v9n2p74

\begin{abstract}
Although a bulk of the literature has examined the methods by which people cope with physical pain, little attention has been devoted to how people learn to respond to pain. The current study examined the relation between college students' reports of parental socialization of pain during childhood and their current coping with pain. One hundred twenty-four ( $65.3 \%$ female) college students reported on two methods of parental socialization they experienced during childhood: a) their mothers' direct responses to their physical pain and b) mothers' modeling of how they coped with their own pain. College students also reported on their own current coping strategies regarding physical pain. Results indicated that retrospective reports of mothers' active coping with their own pain and mothers' promotion responses to their child's pain during childhood significantly positively predicted college students' current active coping. These findings suggest the relevance of both methods of pain socialization (parental modeling and parents' direct responses) for college-age children's current coping with pain.
\end{abstract}

Keywords: socialization, physical pain, emerging adults

\section{Introduction}

A substantial body of research has been conducted regarding how people cope with pain. However, less attention has been paid to how individuals learn specific coping skills. Much like other social processes, children learn to cope with physical pain first in their family of origin with parents among the most influential socializers (Grusec \& Hastings, 2014). Some research has focused on parents' influences on children's pain management, though these studies have focused on only one method of parental socialization (parents' responses to children's pain or parental modeling). To the best of our knowledge, no study to date has simultaneously examined how different methods of parental socialization relate to children's coping with pain. Moreover, although the broad claim that one's early life experiences likely impact later functioning has received some support (Pettitt, Bates, \& Dodge, 1997; Sroufe, 2005), no studies have specifically examined whether parental socialization of pain in childhood, as recalled and reported by the offspring may be relevant for emerging adults as they cope with pain. Thus, in this study, college students' reports of two methods of maternal socialization during childhood are investigated - mothers' direct responses to children's pain and maternal modeling through coping with their own pain, and how they relate to college students' reports of their current coping with pain.

\subsection{Coping With Physical Pain}

Previous studies have demonstrated that across all age groups, people use a variety of coping skills to manage their pain (Lachapelle \& Hadjistavropoulos, 2005). Active coping skills typically involve distraction from the pain or actively trying not to think about it, whereas passive coping mechanisms consist of ruminating about the pain and not actively trying to alleviate it. Most research shows that active coping skills have more beneficial impacts on one's ability to cope with pain than passive coping skills across the lifespan. A substantial body of literature regarding pain coping involves elderly patients with chronic pain because as people age, their bodies begin to deteriorate at a quicker rate and as a result are more likely to experience physical pain. For example, Ersek, Turner, and Kemp (2006) found that older patients tended to use active coping methods such as task persistence, pacing, and coping self-statements to deal with pain, all of which were correlated with higher levels of psychological coping. Coping methods such as relaxation are considered a passive coping method, these were less frequently 
used, and were correlated with lower levels of psychological functioning.

A large body of literature has also examined children's coping with pain, particularly among various patient populations such as those suffering from sickle cell disease (e.g. Barakat, Schwartz, Simon, \& Radcliffe, 2007), fibromyalgia (Kashikar-Zuck et al., 2013), chronic abdominal pain (e.g. Walker, Smith, Garber, \& Claar, 2007), and pain experienced during and after operative medical procedures (Esteve, 2012). This literature has documented that children with chronic pain use a variety of coping mechanisms, but again, passive coping seemed to yield the worst results in terms of pain relief. Walker, Smith, Garber, and Claar (2005) tested three different types of coping in children with chronic pain: passive, active and accommodative. Accommodative coping skills are those that include accepting the pain and encouraging oneself. Findings indicated that passive coping was correlated with more emotional distress whereas accommodative coping was correlated with less distress. Active coping appeared to be more context-specific depending on the other coping mechanisms used in conjunction with it. In another study, an important gender difference was found such that boys reported using active coping more often than girls and active coping negatively correlated with pain intensity. In contrast, girls tended to use internalizing or passive coping mechanisms and felt less successful about being able to cope with their pain.

\subsubsection{Coping with Pain Among Emerging Adults}

Emerging adulthood is a developmental period between adolescence and adulthood that characterizes youth in industrialized societies who in the pursuit of higher education have opted to postpone marriage and parenthood (Arnett, 2000). There is limited research on the way that emerging adults manage pain, though the limited work supports the use of a variety of coping mechanisms such as distraction (active coping), trying to rid themselves of the pain, trying to find greater meaning about their pain (passive coping) and by using advantageous comparison (Firmin Burger, Grigsby, Sherman, \& Croft, 2011). Studies that have examined active and passive coping among emerging adults have been consistent with the literature in showing that passive coping is less adaptive than active coping. Specifically, Jackson, Pope, Nagasaka, Fritch, Iezzi, and Hong (2011) examined the impact of threat on the ability to tolerate pain as well as what coping mechanisms were more effective in dealing with the pain. They used three conditions in which all participants were asked to use a Cold Pressor Test (participants have to submerge their arm above their elbow in ice cold water): One group was told that the pain would be similar to frostbite, a second group was reassured that it would not be very painful, and a control group was told nothing about what the pain experience would be like. The researchers found that participants in the threat condition used more catastrophizing (an example of passive coping method), and less active coping mechanisms such as distraction or ignoring the pain relative to the other groups. Interestingly, participants in the threat group rated their pain sensations the same as all other participants.

Zettle, Hocker and Mick (2005) conducted a similar study using the Cold Pressor Test examining the effect of experiential avoidance on pain management. Specifically for physical pain, experiential avoidance involves intentionally avoiding situations that could induce pain (i.e. restricting activities). They expected that this would be a long-term maladaptive coping mechanism, which would not be beneficial for managing pain. In support of their hypothesis, participants who endorsed experiential avoidance had a much lower pain tolerance compared to those who did not endorse experiential avoidance, despite the fact that both groups rated the pain sensations equally. Those who endorsed experiential avoidance also used catastrophizing as well as praying or hope to cope with the pain. This type of coping is considered passive coping and was not beneficial in helping to reduce their pain experience. Overall, the studies demonstrate that when college students engage in active coping when dealing with pain, they have a higher tolerance for it, even if their pain sensitivity is just as high for those who engage in passive coping (Jackson et al., 2011; Zettle et al., 2005).

\subsection{Parental Socialization of Children's Coping With Pain}

Children acquire norms, rules, behaviors, patterns, values, and skills necessary for competent functioning in a given society through the process of socialization (Mccoby, 2014). Early in life, parents are considered the most influential socialization agents, with peers, teachers, and neighbors contributing to the process as the child gets older. Building on this foundation of socialization in the childhood, the process continues through the lifespan as individuals enter new social environments where employers, romantic partners, and others act as socializers. Although emerging adults may learn new social behaviors, skills, and values as they age, parental socialization during childhood is likely to continue to influence adult behaviors.

Socialization is thought to occur through a variety of methods (Grusec \& Hastings, 2014). Literature on parental socialization of emotion distinguishes between what children learn through parents' direct responses to their behavior, emotional, or physical state (also referred to as direct socialization) and what children learn through observational learning (Bandura, 1977)—observing how parents' behave in particular situations themselves (also 
referred to indirect socialization) (Eisenberg, Cumberland, \& Spinrad, 1998). Literature on parental socialization of children's engagement in physical activity also includes methods such as parental modeling as well as their encouragement and instrumental behaviors directed to facilitate children's physical activity (Pugliese \& Tinsley, 2007). In the literature concerning socialization of pain, researchers have examined either parents' responses to children's pain have been examined (Chambers, Craig, \& Bennett, 2002; Crane \& Martin, 2004; Dasch et al., 2011; Vervoort, Huguet, Verhoeven, \& Goubert, 2011), or parental modeling (Gil, Williams, Thompson and Kinney, 1991; and Dasch et al., 2011) but not both in the same study. In the current study, we examined both of these methods of socialization to examine their relative predictive validity.

\subsubsection{Parent Responses to Children's Pain}

An emerging body of literature examines the relation between parents' direct responses to children's pain and children's coping skills. There are typically three types of parental responses to pain investigated: discouragement, solicitousness, and promotion (well-behaviors) (Huguet, Miró, \& Nieto, 2008). Discouragement, or minimizing the child's pain experience, is typically associated with higher levels of distress (e.g. Claar, Simons, \& Logan, 2007). Solicitousness, or focusing the children's attention on their pain, can also have this effect. Promotion, or behaviors that involve actively distracting from the pain (i.e. doing a fun activity) tend to have better outcomes regarding pain reactions. Achiam-Montal and Lipsitz (2013) found that for children with non-cardiac chest pain, if their parents responded with solicitousness or were more protective in their response to their child's pain (i.e. alleviating them from responsibility), the pain intensity and frequency also increased. However, for children whose parents distracted them from the pain (which promotes wellness behaviors), they experienced pain less intensely and less often. Consistent with these findings, it has been found that heightened attention or solicitousness, especially by the father, towards a child's pain is associated with higher catastrophizing (Crane \& Martin, 2004; Peterson \& Palermo, 2004; Vervoort et al., 2011). Conversely, distraction and promotion of wellness behaviors are correlated with easier child coping (Chambers et al., 2002). In a study by Chambers and colleagues (2002), parents were instructed to either give attention to children's pain, distract their children from pain, or were given no instruction on dealing with their child in pain. The group in which parents attended to the child's pain had the most child complaints of pain followed closely by the no instruction group. These findings suggest that by turning the child's attention away from the pain, the parents are able to help them focus on other activities and forget their pain, even if only temporarily.

\subsubsection{Parental Modeling of Coping}

Only two published studies have examined the relation between parent's' coping with their own pain and children's use of coping strategies. Gil, Williams, Thompson and Kinney (1991) examined the relationship between parental coping and its impact on children with chronic pain. They found that for parents who used "passive adherence" mechanisms such as focusing only on decreasing pain, their children also used this same form of coping with their own pain. In contrast, parents who modeled "coping attempts" such as active coping, their children also used this type of coping with their own pain. Similarly, Dasch et al. (2011) found that if parents used self-blame for coping with their child's illness, the child was more self-critical as well. In addition, if parents gave up on coping all together, children blamed others for their pain. These findings demonstrate that parents' coping strategies with their own pain likely contribute to their children's pain reactions and coping.

\subsection{The Current Study}

The existing literature indicates that both methods of parental socialization (parents' responses to children's pain and parental modeling) are related to children's coping. However, these methods have not been studied together in the same study. Moreover, much of the literature on parental socialization of children's pain focuses on the developmental period of childhood. Although it seems reasonable to assume that parental socialization of pain during childhood, as recalled and reported by the children, may continue to be relevant for emerging adults as they cope with physical pain, this relationship has not been empirically investigated. In the current study, we include both methods of parental socialization (their direct responses to child's pain and modeling), and cross-sectionally examine emerging adults' retrospective reports of their mothers' socialization of pain during childhood and reports of their current coping with pain. Specifically, it was hypothesized that college students' reports of their mothers' active coping during childhood would predict their own current active coping with pain, and that college students' reports of their mothers' passive coping during childhood would predict their own current passive coping. It was also hypothesized that college students' reports of their mothers ' solicitousness or discouragement in response to their pain during childhood would predict the use of current passive coping mechanisms, and reports of parents' promotion responses during childhood would predict college students' current use of active coping. 


\section{Method}

\subsection{Participants}

A total of 124 undergraduate students ( $n=103$ White, $n=3$ Black, $n=9$ Asian, $n=7$ Biracial, and $n=2$ American Indian) from a mid-western university participated in this study. Participants consisted of 43 males and 81 females with a mean age of $19.02(S D=1.26)$ years. A substantial proportion of mothers $(73 \%)$ and fathers $(74 \%)$ of the participants had received a college degree or higher education. A majority of the sample (93\%) had family annual income greater than $\$ 51,000$ (and for $68 \%$ of the sample, it was higher than $\$ 101,000$ ), consistent with or above the US median annual household income \$53, 657 (U.S. Census Bureau, 2014).

\subsection{Procedure}

This study was approved by the IRB at the authors' academic institution. Participants were recruited from psychology department participant pool, and received credit towards introductory psychology course for their participation. Participants arrived at our research lab, the study was explained, and participants provided written informed consent. Subsequently, they completed all of the questionnaires online via Quaitrics at a time and location convenient to them. The questionnaires included a demographic questionnaire, the Inventory of Parent/Caregiver Responses to Children's Pain (Huguet et al., 2008), a modified version of the Vanderbilt Pain Management Inventory (Brown \& Nicassio, 1987) in which participants responded to questions about how their mother coped with pain, and the original version of the Vanderbilt Pain Management Inventory (Brown \& Nicassio, 1987) about how participants themselves cope with pain.

\subsection{Measures}

\subsubsection{Demographic and Health Questionnaire}

This questionnaire was created for this study and included demographic questions such as participant age and gender, parental education and occupation, and family income. Participants were also asked to describe any medical conditions, medical procedures, or physical injury that they have experienced in their life. For each medical condition, procedure, or injury reported, participants were asked the age at which it was experienced, pain experienced $(1=$ no pain to $10=$ the worst imaginable pain $)$, and how they managed the pain. These questions were analyzed to describe our sample.

\subsubsection{Vanderbilt Pain Management Inventory (Brown \& Nicassio, 1987)-Original Self-Report and Modified} Version for Report on Parent

This measure consists of 18 self-report items that assess coping mechanisms of individuals completing the items. The measure has two subscales: active coping ( 7 items; e.g., "distracting attention from the pain," "staying busy or active") and passive coping (11 items; e.g., "praying for relief;" "restricting social activities"). Keeping in mind when they were experiencing pain, participants were asked to indicate (on a scale of $0=$ never do when in pain to $4=$ very frequently do when in pain) how often they responded in a way that would indicate either active or passive coping. Participants completed the original self-report version to assess their current coping mechanisms (Cronbach's alpha for active and passive coping, respectively, $=.79$, and .87 ). This measure was modified such that participants were asked to report on when their mother or primary caregiver was in pain during the participants' childhood, how often they responded in a way that would indicate either active or passive coping. Cronbach's alpha values for active and passive coping, respectively, were .82 , and .89 for the modified version to report on parental coping.

\subsubsection{Inventory of Parent/Caregiver Responses to Children's Pain (Hugguet et al, 2008)}

This parent-report measure consists of 37 items assessing parents' responses to participants' pain. We modified the wording from the parent report format to self-report. The measure is divided into three subscales: discouragement (10 items; e.g., "Tell you that you may be exaggerating"), solicitousness (15 items; e.g., "Accept that in these circumstances you do not need to do your homework"), and wellness/promotion behaviors (12 items; e.g., "Try to distract you by suggesting attractive activities (e.g., plans for the weekend"). Participants were asked to explain using a scale $(0=$ never to $4=$ always $)$ in what way their parents responded to them when they were in physical pain while growing up. The internal consistency of the three subscales was adequate as evident by Cronbach's alpha values for discouragement (.95), solicitousness (.93), and wellness/promotion behaviors (.91).

\section{Results}

Preliminary analyses included examining participants' reports of 1) experience of pain due to a medical condition, medical procedure, or physical injury over the course of their life and 2) current levels of pain. A substantial proportion of the sample reported experiencing a medical condition $(48 \%)$, medical procedure $(54.8 \%)$, or 
physical injury (74\%) over the course of their life. With respect to medical conditions, we categorized the open-ended responses into three categories: chronic conditions (e.g., migraine headaches, scoliosis), acute conditions (e.g., stomach flu, strep throat, Pneumonia, seasonal allergies), and asthma (See Table 1). With respect to medical procedures, we coded the open-ended responses into three categories: dental surgery (the most common was wisdom tooth removal), ear, nose, or throat surgery (e.g., removal of tonsils or adenoids), and other surgeries (e.g., eye surgery, knee surgery). The average age at which participants reported experiencing the medical condition, procedure, or injury, along with the mean reported severity of pain associated with it are provided in Table 1. Participants' open-ended responses regarding how they managed the pain were categorized in five categories: a) use of medication (prescription, over the counter, inhaler), b) other treatment (e.g., wearing a cast, splint or use crutches, physical therapy, using ice on an injured body part), c) rest (e.g., "taking lots of rest," "sleeping"), d) distraction (e.g., "ignore it," "do something else"), and e) passive coping (e.g., "cried," "let it pass," "did nothing"). See Table 1 for the frequency with which each of these were reported. With respect to current experience of pain, the average rating was $3.66(S D=.49$, range $1-10)$ (on a scale of $1=$ no pain, to $10=$ the worst imaginable pain). Of those who rated current pain as 2 or above, for $32.1 \%$ of the participants, pain was related to injury, for $24.5 \%$ the pain was related to illness, and for $35.8 \%$ of the participants pain was related to other causes (i.e., sprained ankle or sore muscles).

3.1 The Interrelations among Maternal Coping, Mother Response to Child Pain, Participants' reported Pain Severity, and Participants' current Coping

Bivariate correlations indicated that as hypothesized, retrospective report of maternal active coping was significantly positively correlated with participants' current active coping, and maternal passive coping was significantly positively correlated with participants' current passive coping (See Table 2). As predicted, reports of maternal solicitousness and discouragement were positively correlated with participants' current passive coping. Also as predicted, maternal promotion was significantly positively correlated with participants' active coping, however, surprisingly, it was also correlated with participants' passive coping. Interestingly, reports of maternal passive coping during childhood and participants' current passive coping were positively related to participants'

Table 1. Participant reports of medical conditions, medical procedures, or physical injuries experienced

\begin{tabular}{|c|c|c|c|}
\hline & Medical condition & Medical procedure & Physical Injury \\
\hline$\%$ of sample reporting & $48 \%$ & $54.8 \%$ & $74 \%$ \\
\hline \multirow{3}{*}{$\begin{array}{l}\text { Types of conditions, } \\
\text { procedures, or injuries }\end{array}$} & Chronic conditions $(5 \%)$ & Dental surgery $(30.6 \%)$ & \multirow{3}{*}{$\begin{array}{l}\text { Various body parts (arm, } \\
\text { hand, wrist, ankle, leg) }\end{array}$} \\
\hline & Acute conditions $(32 \%)$ & ENT surgery $(7.3 \%)$ & \\
\hline & Asthma (11\%) & Other $(16.9 \%)$ & \\
\hline Participant Age $^{1}$ & $12.28(S D=4.77)$ & $14.08(S D=4.53)$ & $13.64(S D=3.55)$ \\
\hline Reported Pain ${ }^{2}$ & $4.78(S D=3.01)$ & $5.33(S D=2.95)$ & $6.74(S D=2.31)$ \\
\hline \multicolumn{4}{|l|}{ Coping with Pain } \\
\hline Medication & $29 \%$ & $37.9 \%$ & $33.9 \%$ \\
\hline Other treatment & $1.4 \%$ & $4.4 \%$ & $24.2 \%$ \\
\hline Rest & $5.6 \%$ & $8.1 \%$ & $7.3 \%$ \\
\hline Distraction & $4.8 \%$ & $2.8 \%$ & $5 \%$ \\
\hline Passive coping & $7.2 \%$ & $1.6 \%$ & $4 \%$ \\
\hline
\end{tabular}

\footnotetext{
${ }^{1}$ for chronic conditions, age of onset was used, for multiple surgeries or injuries data for first injury or surgery are used as more than one were uncommon. The age range was from 2-20 years.

${ }^{2}$ Pain was reported on a scale of $1=$ no pain to $10=$ worst imaginable pain. The range for reported pain for medical condition, medical procedure, and physical injury was 1-10.
} 
Table 2. Means, standard deviations, and correlations among key study variables

\begin{tabular}{|c|c|c|c|c|c|c|c|c|c|}
\hline & 1 & 2 & 3 & 4 & 5 & 6 & 7 & 8 & 9 \\
\hline 1. Active Coping- Mother & --- & & & & & & & & \\
\hline 2. Passive Coping- Mother & .18 & --- & & & & & & & \\
\hline 3. Mothers' Solicitousness & .17 & $.38^{*}$ & --- & & & & & & \\
\hline 4. Mothers' Discouragement & .12 & .14 & -.19 & --- & & & & & \\
\hline 5. Mothers' Promotion & $.35^{*}$ & .15 & $.59^{*}$ & .77 & --- & & & & \\
\hline 6. Active Coping- Participant & $.67 *$ & .10 & -.00 & .09 & $.37 *$ & --- & & & \\
\hline 7. Passive Coping- Participant & .09 & $.60^{*}$ & $.36^{*}$ & $.34 *$ & $.28^{*}$ & 0.13 & --- & & \\
\hline $\begin{array}{l}\text { 8. Participant's pain related to medical } \\
\text { condition/procedure/ injury }\end{array}$ & .04 & $.34 * *$ & .18 & .10 & .11 & .09 & $.31 *$ & -- & \\
\hline 9. Participants' current pain & .18 & $.20^{*}$ & .05 & .13 & -.04 & .13 & .09 & .19 & -- \\
\hline$M$ & 2.88 & 2.21 & 3.23 & 1.83 & 3.11 & 3.01 & 2.27 & 5.40 & 3.66 \\
\hline$(S D)$ & $(.71)$ & $(.64)$ & $(.77)$ & $(.84)$ & $(.79)$ & $(.62)$ & $(.61)$ & (2.09) & (.49) \\
\hline
\end{tabular}

reported pain experienced due to medical condition, procedure, or physical injury in their life. Reports of maternal passive coping during childhood was also significantly positively correlated with participants' current reported pain.

\subsection{Maternal Coping and Responses to Child Pain as Predictors of College Students' Current Coping}

Hierarchical multiple regression analysis was used to test whether retrospective reports of maternal active coping and promotion predicted college students' current active coping. In the first step, mothers' active coping was entered and in step 2, mothers' promotion responses were added. The results indicated that both predictors explained $48 \%$ of the variance in college students' active coping, with mothers' active coping $(B=.50)$ as a stronger predictor of college students' current active coping than promotion responses $(B=.10)$ (see Table 3$)$.

Table 3. Retrospective reports of mothers' active coping and promotion responses as predictors of college students' current active coping

\begin{tabular}{llllll}
\hline & $B$ & $S E$ & $t$ & $R^{2}$ & $F$ \\
\hline Step 1 & & & & .44 & $87.16^{* * *}$ \\
Mothers' active coping & .58 & .06 & $9.34^{* * *}$ & & \\
\hline Step 2 & & & & .48 & $50.81^{* * *}$ \\
Mothers' active coping & .50 & .07 & $7.45^{* * *}$ & & \\
Mothers' promotion responses & .10 & .04 & $2.91^{*}$ & & \\
\hline$* \mathrm{p}<.05, * * * \mathrm{p}<.001$. & & & &
\end{tabular}

Additionally, a hierarchical multiple regression analysis was used to test whether retrospective reports of parental passive coping, solicitousness, and discouragement predicted college students' current passive coping. In the first step, mothers' passive coping was entered, in step 2, mothers' discouragement was added, and in step 3, mothers' solicitousness was added. The results indicated that the three predictors explained $51 \%$ of the variance, with mothers' passive coping as the strongest predictor $(B=.41)$, followed by discouragement $(B=.28)$, followed by solicitousness $(B=.18)$ (see Table 4$)$. 
Table 4. Retrospective reports of mothers' passive coping, solicitousness, and discouragement as predictors of college students' current passive coping

\begin{tabular}{|c|c|c|c|c|c|}
\hline & $B$ & $S E$ & $t$ & $R^{2}$ & $F$ \\
\hline Step 1 & & & & .37 & $60.56^{* * *}$ \\
\hline Mothers' passive coping & .58 & .08 & $7.78^{* * *}$ & & \\
\hline Step 2 & & & & .44 & $40.12 * * *$ \\
\hline Mothers' passive coping & .55 & .07 & $7.77 * * *$ & & \\
\hline Mothers' discouragement & .23 & .06 & $3.55^{* *}$ & & \\
\hline Step 3 & & & & .51 & $36.17 * * *$ \\
\hline Mothers' passive coping & .41 & .08 & $5.47 * * *$ & & \\
\hline Mothers' discouragement & .28 & .06 & $4.55^{* * *}$ & & \\
\hline Mothers' solicitousness & .18 & .05 & $4.01 * * *$ & & \\
\hline
\end{tabular}

\section{Discussion}

The aim of the current study was to examine retrospective reports of two methods of maternal socialization (mothers' responses to children's pain, and maternal modeling) as predictors of emerging adults' current coping with physical pain in a community sample of college students. Preliminary analyses indicated that a substantial proportion of the sample had experienced physical pain related to a medical condition, a medical procedure, or physical injury over the course of their life. Mean levels of pain experienced due to the medical condition, procedure or injury that participants reported were between 4.78 and 6.74 on a scale of 1 (no pain) to 10 (the worst imaginable pain) indicating that participants in this sample experienced moderate to severe pain at some point during their life. Using an open-ended format, participants were also asked how they managed the pain they experienced due the medical condition, procedure, or injury they reported. Interestingly, the most common response was the use of medication (over the counter or prescription) or other medical treatment. In this open-ended format, participants were less likely to mention specific coping strategies (either active or passive). Using forced-choice format (i.e., their ratings on Vanderbilt Pain Management Inventory) they reported using both active and passive coping strategies (with mean ratings of 3.01 and 2.27 , respectively on a 5-point scale). Forced-choice format may allow better retrieval of the coping strategies used

As predicted, regression analyses indicated that college students' retrospective reports of their mothers' active coping during childhood and maternal promotion responses predicted college students' current active coping. Moreover, college students' retrospective reports of their mothers' passive coping during childhood along with maternal solicitousness and discouragement predicted college students' current passive coping. These findings suggests that reports of both methods of parental socialization (their direct responses to the child's physical pain and their modeling of their own coping with pain) are relevant and predict their college-aged children's coping strategies. These findings are consistent with previous research documenting the relationship between parental coping and child coping (Gill et al., 1991), as well as between promotion responses and active coping (Chambers et al., 2002) and discouragement and solicitousness and passive coping (Crane \& Martin, 2004; Peterson \& Palermo, 2004; Vervoort et al., 2011). If a child perceives their parents as dwelling on and talking about the pain, it is likely that they will repeat those behaviors and carry them into their adult life. The same is true for active coping mechanisms. If a child experiences their parents going about their day as normal while experiencing pain, they are likely to exhibit the same behavior.

Findings also indicated that reports of mothers' active coping were a stronger predictor of college students' current active coping than promotion responses, and that reports of mothers' passive coping were the strongest predictor, followed by discouragement, followed by solicitousness for college students' current passive coping. These findings may suggest that maternal modeling of coping with pain may be more relevant than their direct responses to their children's pain for children's coping strategies. However, it is important to be cautious in making such a claim from the current data. Our data are cross-sectional and involve reports of a single respondent that are subject to shared method variance (i.e., participants reports of their mothers' coping with pain may be similar to their reports of their own coping with pain simply because they are reporting on both variables). The present findings should be explored further in future research that involves longitudinal design and multiple reports of parental 
socialization as well as of youth's coping strategies to examine if these findings would hold.

Correlational analyses indicated that reports of mothers' passive coping during childhood and college students' current passive coping were positively related to pain experienced due to medical condition, procedure, or physical injury in their life. Reports of maternal passive coping during childhood was also significantly positively correlated with participants' current reported pain. Passive coping strategies may be ineffective in effectively managing pain and it is possible that individuals who observe others as using passive coping themselves learn to use passive coping, which may be ineffective in managing their pain and they may experience higher severity of pain. Our data are cross-sectional and involve reports of a single respondent, and thus, it is not possible to make any causal claims. However, our data suggest associations among reports of maternal passive coping, individuals' own passive coping, and individual's experienced pain that should be explored in future research with longitudinal design and multiple respondents.

\subsection{Limitations and Future Directions}

We relied on college students' retrospective reports of parental socialization during childhood, which are subject to two sets of biases: First, children may subjectively experience the same objective parent behavior in different ways, and thus, we assessed college students' subjective representation of parent behavior rather than actual parent behavior. Second, there may be bias in recall of parent behavior such that participants' current relationship with the parent as well as their current coping with pain may interfere with them accurately recalling how their mothers' responded to their pain and how they coped with their own pain.

A second limitation of the study was that our sample was primarily Caucasian, middle and upper middle-class college students. This group does not represent emerging adult population across United States, in particular, those who are racially and ethnically diverse, those who are from lower social class, or those who do not attend college. Future research with diverse populations from the United States is needed. A third limitation was that we examined the relation between reports maternal socialization and college students' current coping with pain cross-sectionally, and that a single respondent (college students) reported on all study variables. Future studies may utilize parents' reports of their own coping and response styles, and prospectively examine the relation between parental socialization and children's coping with pain. Further, future research may examine how college students' active and passive coping strategies are related to their daily functioning, specifically their participation in academic, work, and social activities and responsibilities. Finally, future research also examine parental socialization of children's physical pain along with socialization of other emotional and behavioral states. Scholars have argued that socialization is a domain-specific process (Grusec \& Davidov, 2010), and it would be beneficial to examine similarities and differences in parental socialization approaches to children's physical pain as compared to emotional distress.

Despite limitations, the present study was the first to simultaneously examine reports of different methods of parental socialization of pain, and to assess which methods may be more relevant for college-aged adults' current coping. This line of research has important implications for developing intervention or education programs for both parents and youth in using more effective coping strategies for everyday experiences of pain, as well as for pain related to specific medical conditions, procedures, or physical injuries.

\section{References}

Achiam-Montal, M., \& Lipsitz, J. D. (2014). Does parental response to children's pain moderate the association between pain severity and functional disability? An examination of noncardiac chest pain. Journal of Pediatric Psychology, 39, 35-44. https://doi.org/10.1093/jpepsy/jst068

Arnett, J. J. (2014). Socialization in emerging adulthood: from the family to the wider world, from socialization to self-socialization. In J. E. Grusec and P. D. Hastings (Eds), Handbook of socialization: Theory and research (2nd ed., pp. 85-108). New York: Guilford Press.

Bandura, A. (1977). Social learning theory. Englewood Cliffs, N.J.: Prentice Hall.

Buenaver, L. F., Edwards, R. R., Smith, M. T., Gramling, S. E., \& Haythornthwaite, J. A. (2008). Catastrophizing and pain-coping in young adults: Associations with depressive symptoms and headache pain. Journal of Pain, 9, 9311-319. https://doi.org/10.1016/j.jpain.2007.11.005

Chambers, C. T., Craig, K. D., \& Bennett, S. M. (2002). The impact of maternal behavior on children's pain experiences: An experimental analysis. Journal of Pediatric Psychology, 27, 293-301. https://doi.org/10.1093/jpepsy/27.3.293

Claar, R. L., Simons, L. E., \& Logan, D. E. (2008). Parental response to children's pain: The moderating impact of 
children's emotional distress on symptoms and disability. Pain, 13, $172-179$. https://doi.org/10.1016/j.pain.2007.12.005

Crane, C., \& Martin, M. (2004). Social learning, affective state and passive coping in irritable bowel syndrome and inflammatory bowel disease. General Hospital Psychiatry, 2, 50-58. https://doi.org/10.1016/j.genhosppsych.2003.07.005

Dasch, K., Russell, H., Kelly, E., Gorzkowski, J., Mulcahey, M., Betz, R., \& Vogel, L. (2011). Coping in caregivers of youth with spinal cord injury. Journal of Clinical Psychology In Medical Settings, 18, $361-371$. https://doi.org/10.1007/s10880-011-9258-z

DeNavas-Walt, Carmen and Bernadette D. Proctor, U.S. Census Bureau. (2014). Income and Poverty in the United States: 2014. U.S. Government Printing Office, Washington, DC, 2015. Retrieved from https:/www.census.gov/content/dam/Census/library/publications/2015/demo/p60-252.pdf

Eisenberg, N., Cumberland, A., \& Spinrad, T. L. (1998). Parental socialization of emotion. Psychological Inquiry, 9(4), 241-273. https://doi.org/10.1207/s15327965pli0904_1

Esteve, R. V. (2012). Children's pain perspectives. Child: Care, Health \& Development, 38, $441-452$. https://doi.org/10.1111/j.1365-2214.2011.01297.x

Firmin, M. W., Burger, A. J., Grigsby, M. E., Sherman, A. L., \& Croft, J. N. (2011). Coping constructs related to college students with chronic pain. Journal of Ethnographic \& Qualitative Research, 6, 32-44.

Grusec, J. E., \& Davidov, M. (2010). Integrating different perspectives on socializationtheory and research: A domain-specific approach. Child $\quad$ Development, $287-709$. https://doi.org/10.1111/j.1467-8624.2010.01426.x

Grusec J. E., \& Hastings, P. D. (2014). Preface. In J. E. Grusec and P. D. Hastings (Eds), Handbook of socialization: Theory and research (2nd ed.). New York: Guilford Press.

Huguet, A., Miró, J., \& Nieto, R. (2008). The inventory of parent/caregiver responses to the children's pain experience (IRPEDNA): Development and preliminary validation. Pain, 13, 128-139. https://doi.org/10.1016/j.pain.2007.04.004

Jackson, T., Pope, L., Nagasaka, T., Fritch, A., Iezzi, T., \& Hong, C. (2005). The impact of threatening information about pain on coping and pain tolerance. British Journal of Health Psychology, 10, 441-451. https://doi.org/10.1348/135910705X27587

Kapoor, S., Thorn, B., \& Eyer, J. (2013). College students with chronic or recurrent pain: a qualitative exploration of their experiences. Journal of Pain, 14, 1. https://doi.org/10.1016/j.jpain.2013.01.753

Kashikar-Zuck, S., Sil, S., Lynch-Jordan, A. M., Ting, T. V., Peugh, J., Schikler, K. N., ... \& Lovell, D. J. (2013). Changes in pain coping, catastrophizing, and coping efficacy after cognitive-behavioral therapy in children and adolescents with juvenile fibromyalgia. The Journal of Pain, 14(5), $492-501$. https://doi.org/10.1016/j.jpain.2012.12.019

Lachapelle, D. L., \& Hadjistavropoulos, T. (2005). Age-related differences among adults coping with pain: Evaluation of a developmental life-context model. Canadian Journal of Behavioural Science, 37, $123-137$. https://doi.org/10.1037/h0087250

Lynch, A. M., Kashikar-Zuck, S., Goldschneider, K. R., \& Jones, B. A. (2007). Sex and age differences in coping styles among children with chronic pain. Journal of Pain and Symptom Management, 33, $208-216$. https://doi.org/10.1016/j.jpainsymman.2006.07.014

Mccobby, E. E. (2014). Historical overview of socialization research and theory. In J. E. Grusec and P. D. Hastings (Eds), Handbook of socialization: Theory and research (2nd ed., pp. 3-31). New York: Guilford Press.

Peterson, C. C., \& Palermo, T. M. (2004). Parental reinforcement of recurrent pain: The moderating impact of child depression and anxiety on functional disability. Journal of Pediatric Psychology, 29, 331-341. https://doi.org/10.1093/jpepsy/jsh037

Pettitt, G. S., Bates, J. E. \& Dodge, K. A. (1997). Supportive parenting, Ecological Context, and Children's Adjustment: A seven-Year Longitudinal Study. Child Development, 68(5), 908-923. https://doi.org/10.2307/1132041

Pugliese, J. \& Tinsley, B. (2007). Parental Socialization of Child and Adolescent Physical Activity: A Meta-Analysis. Journal of Family Psychology, 21, 331-343. https://doi.org/10.1037/0893-3200.21.3.331 
Simons, L., Claar, R., \& Logan, D. (2008). Chronic pain in adolescence: Parental responses, adolescent coping, and their impact on adolescents pain behaviors. Journal of Pediatric Psychology, 33, 894-904. https://doi.org/10.1093/jpepsy/jsn029

Sroufe, L. A. (2005). Attachment and development: A prospective, longitudinal study from birth to adulthood. Attachment and Human Development, 7 (4), 349-367. https://doi.org/10.1080/14616730500365928

Vervoort, T., Goubert, L., \& Crombez, G. (2010). Parental responses to pain in high catastrophizing children: The moderating effect of child attachment. Journal of Pain, 11, 755-763. https://doi.org/10.1016/j.jpain.2009.11.012

Vervoort, T., Huguet, A., Verhoeven, K., \& Goubert, L. (2011). Mothers' and fathers' responses to their child's pain moderate the relationship between the child's pain catastrophizing and disability. Pain, 152, 786-793. https://doi.org/10.1016/j.pain.2010.12.010

Walker, L. S., Smith, C. A., Garber, J., \& Claar, R. L. (2005). Testing a model of pain appraisal and coping in children with chronic abdominal pain. Health Psychology, 24, 364-374. https://doi.org/10.1037/0278-6133.24.4.364

Walker, L. S., Smith, C. A., Garber, J., \& Claar, R. L. (2007). Appraisal and coping with daily stressors by pediatric patients with chronic abdominal pain. Journal of Pediatric Psychology, 32(2), $206-216$. https://doi.org/10.1093/jpepsy/jsj124

White, C. P., Mendoza, J., White, M. B., \& Bond, C. (2009). Chronically ill mothers experiencing pain: Relational coping strategies used while parenting young children. Chronic Illness, 5, 33-45. https://doi.org/10.1177/1742395309102820

Zettle, R. D., Hocker, T. R., \& Mick, K. A. (2005). Differential strategies in coping with pain as a function of level of experiential avoidance. Psychological Record, 55, 511-524. https://doi.org/10.1007/BF03395524

\section{Copyrights}

Copyright for this article is retained by the author(s), with first publication rights granted to the journal.

This is an open-access article distributed under the terms and conditions of the Creative Commons Attribution license (http://creativecommons.org/licenses/by/4.0/). 